\title{
Physiological and molecular responses to an acute bout of reduced- exertion high-intensity interval training (REHIT)
}

Metcalfe $\mathrm{RS}^{1,3}$, Koumanov $\mathrm{F}^{2}$, Ruffino $\mathrm{JS}^{1}$, Stokes $\mathrm{KA}^{1}$, Holman $\mathrm{GD}^{2}$, Thompson $\mathrm{D}^{1}$, Vollaard $\mathrm{NBJ}^{1}$

${ }^{1}$ Department for Health, University of Bath, UK

${ }^{2}$ Department of Biology \& Biochemistry, University of Bath, UK

${ }^{3}$ Sport and Exercise Sciences Research Institute, School of Sport, University of Ulster, UK

Corresponding Author:

Dr Niels Vollaard

Department for Health

University of Bath

Bath, BA2 7AY, UK

Phone: 01225384649

Email: n.vollaard@bath.ac.uk

Accepted for publication in European Journal of Applied Physiology published by Springer. Publisher policy allows this work to be made available in this repository; The original publication is available at Springer via http://dx.doi.org/10.1007/s00421-015-3217-6 


\section{ABSTRACT}

Purpose: We have previously shown that six weeks of reduced-exertion high-intensity interval training (REHIT) improves $\dot{\mathrm{V}}_{2}$ max in sedentary men and women, and insulin sensitivity in men. Here we present two studies examining the acute physiological and molecular responses to REHIT.

Methods: In Study 1, five men and six women (age: $26 \pm 7$ y, BMI: $23 \pm 3 \mathrm{~kg} \cdot \mathrm{m}^{-2}, \dot{\mathrm{VO}}_{2}$ max: $51 \pm 11 \mathrm{ml} \cdot \mathrm{kg}^{-1} \cdot \mathrm{min}^{-1}$ ) performed a single 10-min REHIT cycling session (60 $\mathrm{W}$ and two 20-s 'allout' sprints), with vastus lateralis biopsies taken before and 0, 30 and 180 min post-exercise for analysis of glycogen content, phosphorylation of AMPK, p38 MAPK and ACC, and gene expression of PGC1 $\alpha$ and GLUT4. In Study 2, eight men $\left(21 \pm 2 \mathrm{y} ; 25 \pm 4 \mathrm{~kg} \cdot \mathrm{m}^{-2} ; 39 \pm 10 \mathrm{ml} \cdot \mathrm{kg}\right.$ ${ }^{1}$. $\mathrm{min}^{-1}$ ) performed three trials (REHIT, 30 min cycling at $50 \%$ of $\mathrm{VO}_{2} \max$, and a resting control condition) in a randomised cross-over design. Expired air, venous blood samples, and subjective measures of appetite and fatigue were collected before and 0, 15, 30 and $90 \mathrm{~min}$ post-exercise.

Results: Acutely, REHIT was associated with a decrease in muscle glycogen, increased ACC phosphorylation, and activation of PGC1 $\alpha$. When compared to aerobic exercise, changes in $\dot{\mathrm{VO}}_{2}$, RER, plasma volume, and plasma lactate and ghrelin were significantly more pronounced with REHIT, whereas plasma glucose, NEFAs, PYY, and measures of appetite were unaffected.

Conclusions: Collectively these data demonstrate that REHIT is associated with a pronounced disturbance of physiological homeostasis and associated activation of signalling pathways, which together may help explain previously observed adaptations once considered exclusive to aerobic exercise.

\section{Keywords:}

HIT, glycogen, signalling pathways, AMPK, exercise metabolism, energy balance

\section{Abbreviations:}

ACC: Acetyl-CoA carboxylase, AMPK: AMP-activated protein kinase, ANOVA: analysis of variance, ATP: adenosine triphosphate, AUC: area under the curve, $\beta$-HAD: $\beta$-hydroxy acylCoA dehydrogenase, BMI: body-mass index, COX IV: cytochrome $c$ oxidase, EPOC: excess post-exercise oxygen consumption, GAPDH: glyceraldehyde 3-phosphate dehydrogenase, GLUT4: glucose transporter 4, HIT: high-intensity interval training, HRmax: maximal heart rate, p38 MAPK: p38 mitogen-activated protein kinase, NEFA: non-esterified fatty acid, PCR: polymerase chain reaction, PGC1 $\alpha$ : peroxisome proliferator-activated receptor gamma coactivator 1-alpha, PYY: peptide YY, REHIT: reduced-exertion HIT, RER: respiratory exchange ratio, RPE: rating of perceived exertion, $\mathrm{V}_{2}$ max: maximal oxygen uptake capacity. 


\section{INTRODUCTION}

Despite clear recommendations on the minimal amount of physical activity for achieving health benefits and reducing risk of chronic disease (Garber et al. 2011), the majority of people in the developed world remain largely sedentary (Tucker et al. 2011; Colley et al. 2011; Allender et al. 2008). As 'lack of time' has been identified as one of the main barriers to becoming and remaining physically active (Korkiakangas et al. 2009; Reichert et al. 2007), over the past decade research has focused on high-intensity interval training (HIT) as a timeefficient alternative to aerobic exercise (Gillen and Gibala 2014). Although initial studies have convincingly demonstrated equal or better health benefits with various HIT protocols compared to much larger volumes of aerobic exercise (Gibala et al. 2006; Rakobowchuk et al. 2008; Shepherd et al. 2013; Cocks et al. 2013; Burgomaster et al. 2008; Trapp et al. 2008; Gillen et al. 2013; Little et al. 2010), these HIT protocols tend to be very strenuous and as such are unlikely to be adhered to by sedentary populations. Furthermore, most HIT protocols are not as time-efficient as sometimes claimed, with the total time per exercise session generally exceeding 20-30 minutes (Gibala et al. 2006; Rakobowchuk et al. 2008; Shepherd et al. 2013; Cocks et al. 2013; Burgomaster et al. 2008; Trapp et al. 2008; Gillen et al. 2013; Little et al. 2010). However, more recently we (Metcalfe et al. 2012) and others (Gillen et al. 2014; Hazell et al. 2010; Tjønna et al. 2013) have demonstrated that performing HIT protocols consisting of fewer and/or shorter sprints does not appear to attenuate the associated training adaptations, as long as the exercise intensity remains high.

To date, the lowest amount of high-intensity exercise demonstrated to be associated with health benefits has been our reduced-exertion HIT protocol (REHIT), which incorporates two 20-s all-out cycle sprints in a 10-min low-intensity exercise session (Metcalfe et al. 2012). Six weeks of three weekly REHIT sessions improved $\dot{\mathrm{VO}}_{2}$ max in sedentary men and women, as well as insulin sensitivity in men. Support for these results was recently provided by Gillen et al. (2014) who used a similar protocol but with three 20-s sprints instead of two. Similar improvements in $\mathrm{V}_{2}$ max compared to our study were associated with further aerobic adaptations in skeletal muscle (increased protein content of COX IV and increased maximal activities of citrate synthase and $\beta-H A D$ ). A sex difference was again apparent in measures of glycaemic control, potentially partially explained by the significantly lower training-induced increase in muscle GLUT4 levels in women compared with men. As the REHIT protocol is both highly time-efficient (total training time of 30 min per week) and manageable (mean RPE 13 or 'somewhat hard') it may provide a suitable alternative or adjunct to current physical activity recommendations. However, further larger studies will be needed to confirm these initial positive observations (Metcalfe et al. 2012; Gillen et al. 2014).

At the same time it also needs to be established why such a small volume of high-intensity exercise (total 40-60 s per session) appears to be effective for promoting beneficial skeletal muscle and whole-body adaptations. At the molecular level, adaptation to exercise is thought to result from cumulative transient increases in gene transcription (and protein synthesis) that follow each acute exercise bout, with the metabolic perturbations induced by contraction activating various signalling kinases which, in turn, target downstream transcriptional coactivators and regulators (Perry et al. 2010). Previous studies investigating more time-consuming and more strenuous HIT protocols have demonstrated a molecular 
response which includes a 20-30\% drop in muscle glycogen concentrations, substantial lactate accumulation, an altered ATP:ADP ratio, and increases in AMPK activity (1.4-fold), p38 MAPK activity (1.5-fold), and a 6-fold increase in mRNA expression of PGC1 $\alpha$ (Esbjornsson-Liljedahl et al. 1999; Gibala et al. 2009; Parolin et al. 1999). Furthermore, the acute disturbance in muscle metabolism is associated with a substantial disruption of wholebody/systemic homeostasis, including a prolonged increase in post-exercise oxygen consumption (EPOC), and alterations in the appetite regulating hormones acylated ghrelin and peptide $Y Y$ in a direction which would be expected to suppress appetite (Hazell et al. 2012; Williams et al. 2013; Deighton et al. 2013). Such changes may explain why studies have observed beneficial alterations in body composition following several weeks of HIT (Whyte et al. 2010; Gillen et al. 2013; Heydari et al. 2012; Trapp et al. 2008). However, to date little is known about whether these acute responses to 'classic' HIT are retained with shorter, more manageable protocols such as REHIT. This represents an important area of research since it may provide information about the initial stimuli responsible for the activation of signalling pathways and chronic phenotypic adaptations.

Here we present two studies investigating the acute responses to REHIT. In the first study we measured glycogen degradation, AMPK and p38 MAPK activation, and changes in PGC1 $\alpha$ and GLUT4 gene expression in skeletal muscle following REHIT. Given that glycogen utilisation appears to be most prominent during the first 15-s of the first sprint during a repeated sprint protocol (Parolin et al. 1999), and glycogen concentrations appear to play an important role in the regulation of AMPK and p38 MAPK (Philp et al. 2012), we hypothesised that REHIT would be associated with a $20-30 \%$ reduction in muscle glycogen, activation of AMPK and p38 MAPK, and increases in GLUT4 and PGC1 $\alpha$ gene expression. In study 2, we examined differences between REHIT and a bout of moderate-intensity aerobic exercise in a range of post-exercise physiological responses including oxygen consumption and appetite regulating hormones. As intensity has been highlighted as the key determinant of exercise-induced changes in these variables (Hazell et al. 2012; Deighton et al. 2013), we hypothesised that REHIT would be associated with a more pronounced disturbance of physiological homeostasis and a greater suppression of appetite compared to aerobic exercise. 


\section{METHODS}

\section{Study 1}

\section{Subjects}

Twelve healthy active men $(n=6)$ and women $(n=6)$ agreed to take part in Study 1 . We were unable to obtain usable muscle biopsies in one male subject so the final sample size was $\mathrm{n}=11$ (men: mean \pm SD age $26 \pm 7 \mathrm{y}, \mathrm{BMI} 23 \pm 2 \mathrm{~kg} \cdot \mathrm{m}^{-2}, \dot{\mathrm{V}}_{2} \max 58 \pm 13 \mathrm{ml} \cdot \mathrm{kg}^{-1} \cdot \mathrm{min}^{-1}$; women: age $\left.26 \pm 7 \mathrm{y}, \mathrm{BMI} 23 \pm 3 \mathrm{~kg} \cdot \mathrm{m}^{-2}, \mathrm{VO}_{2} \max 46 \pm 5 \mathrm{ml} \cdot \mathrm{kg}^{-1} \cdot \mathrm{min}^{-1}\right)$. The study protocol received ethics approval from the NHS South West Research Ethics Committee (NHS REC Reference: $12 / \mathrm{SW} / 0018$ ) and all subjects provided written informed consent after being advised of the full experimental procedures and potential risks.

\section{Pre-experimental procedures}

Prior to the main experimental trial subjects visited the lab on three separate occasions. During the initial visit maximal oxygen uptake capacity $\left(\mathrm{V}_{2} \mathrm{max}\right)$ was determined during a continuous incremental ramp test to exhaustion ( $30 \mathrm{~W} \cdot \mathrm{min}^{-1} \mathrm{ramp}$ ) on an electrically-braked cycle ergometer (Lode, Excalibur Sport, the Netherlands) with $\dot{\mathrm{V}}_{2}$ measured continuously using an online metabolic cart (ParvoMedics TrueOne 2400, Utah, USA). $\dot{V}_{2}$ max was determined as the highest value of a 15-breath rolling average. In all tests two or more of the following criteria were met: heart rate within 10 beats of age-predicted maximum, RER $\geq$ $1.10, \mathrm{RPE} \geq 19$, and/or volitional exhaustion.

On separate days, with at least 2 days rest in between, each participant performed two REHIT familiarisation sessions on a mechanically-braked cycle ergometer (Monark 894e, Vansbro, Sweden), consisting of $10 \mathrm{~min}$ of cycling at $60 \mathrm{~W}$ interspersed with two all-out sprints against a resistance equivalent to $7.5 \%$ of bodyweight. Just before each sprint subjects increased their pedal cadence to their maximal speed, the braking torque was applied to the ergometer, and subjects sprinted maximally against the braking torque for 10 (first visit) or $20 \mathrm{~s}$ (second visit) as previously described (Metcalfe et al. 2012). The second familiarisation session was identical to that used during the main experimental trial.

\section{Experimental procedures}

Between 1 and 3 weeks following the final familiarisation, and having refrained from strenuous physical activity ( 2 days) and alcohol and caffeine ( 1 day), subjects attended the lab at 8 am following an overnight fast. After resting quietly for 15 min two small incisions ( $5 \mathrm{~mm}$ ) were made in the vastus lateralis of one leg under local anaesthetic (1\% lidocaine) for collection of muscle biopsy samples using the Bergstrom needle technique adapted for suction (Tarnopolsky et al. 2011). One of these incisions was used for collection of the baseline muscle sample and immediately closed with steristrips, whilst the second was initially covered with sterile gauze and used for collection of the sample immediately after performing the 10-min REHIT bout (as described above). Power output during the sprints was recorded continuously using Monark Anaerobic Test Software (Monark, Vansbro, Sweden), and used to calculate peak, average and end power output for each sprint. Further muscle biopsy samples were collected at $30 \mathrm{~min}$ and $180 \mathrm{~min}$ post-exercise through separate incisions and on the opposite leg to the first two samples. The starting leg for collection of 
the muscle samples was counterbalanced and the first biopsy on each leg was always taken at a more distal point to the second ( $\sim 3 \mathrm{~cm}$ between incisions). Following each muscle biopsy procedure, the muscle sample was immediately snap-frozen and stored in liquid nitrogen until subsequent analysis. Throughout the recovery period subjects rested and remained fasted (i.e. water only).

\section{Skeletal muscle glycogen analysis}

Approximately $20 \mathrm{mg}$ of frozen wet tissue was freeze-dried, powdered, and dissected free of visible blood and connective tissue. Samples were then suspended in $\mathrm{dH}_{2} \mathrm{O}(0.5 \mathrm{mg} / 100 \mu \mathrm{l})$ and homogenised on ice; first manually using a dounce homogeniser (30-40 passes) and then by sonication ( $4 \times 10$-s bursts at 10 microns with $50 \mathrm{~s}$ in between bursts). Homogenates were then heated at $95^{\circ} \mathrm{C}$ for $5 \mathrm{~min}$ and centrifuged at $13000 \mathrm{rpm}$ for $5 \mathrm{~min}$ before the glycogen content of the resulting supernatant was determined in duplicate using an enzymatic assay adapted for fluorimetry according to the manufacturer's instructions (Abcam Glycogen Assay Kit (ab65620), Cambridge, UK). Glycogen concentrations were expressed as glucosyl units ( $\mathrm{mmol} \cdot \mathrm{kg}^{-1} \mathrm{dry}$ weight) and background glucose concentrations were determined and subtracted from the final glycogen readings. The intra-assay coefficient of variation was $\sim 3 \%$. Due to poor sample quality we were unable to analyse glycogen levels for two subjects at $t=0$. As the level of glycogen did not differ between the three post-exercise time-points the individual glycogen value for $t=30$ was used for this timepoint for the purpose of statistical analysis.

\section{Western blotting}

For each sample approximately $30 \mathrm{mg}$ of frozen wet tissue was freeze-dried, powdered and dissected free of visible blood and connective tissue, and added to ice cold lysis buffer (20 $\mathrm{mM}$ Tris (pH 7.8), $137 \mathrm{mM} \mathrm{NaCl}, 2.7 \mathrm{mM} \mathrm{KCl}, 1 \mathrm{mM} \mathrm{MgCl} 2,1 \%$ Triton X-100, 10\% (w/v) glycerol, $1 \mathrm{mM}$ EDTA, $1 \mathrm{mM}$ dithiothreitol) supplemented with protease (Thermo Scientific) and phosphatase inhibitor cocktail (Millipore). The samples were homogenised on ice using a dounce homogeniser (40-50 passes) and incubated for $1 \mathrm{hr}$ at $4^{\circ} \mathrm{C}$ with continuous rotation. Samples were then centrifuged at $13000 \mathrm{rpm}$ for $5 \mathrm{~min}$ and the supernatants collected. The protein content of the supernatant was determined using a bicinchoninic acid assay (BCA) (Thermo Scientific). For each blot equal amount of protein (50 $\mathrm{\mu g}$ of each sample) was loaded per lane and separated by SDS-PAGE on 7\% (p-ACC ${ }^{579}$ (acetyl CoA carboxylase), p-AMPK ${ }^{\top 172}$ and total AMPK) or 10\% (p-p38 MAPK $^{\top 180}$ and total p38 MAPK) Trisglycine SDS-polyacrylamide gels. Gels were electroblotted by semi-dry transfer onto nitrocellulose membranes. After transfer, membranes were washed in TBS-T (Tris-buffered saline buffer containing Tween 20;0.09\% NaCl, $1 \mathrm{M}$ Tris- $\mathrm{HCl} \mathrm{pH} \mathrm{7.4,0.1 \%} \mathrm{Tween} \mathrm{20,)} \mathrm{and}$ then incubated for $1 \mathrm{hr}$ in a blocking solution consisting of 5\% skimmed milk (Marvel, Premier International Foods Ltd, UK) made up with TBS-T. Membranes were then incubated overnight at $4^{\circ} \mathrm{C}$ with primary antibodies (1:1000 dilution) against $\mathrm{p}-\mathrm{AMPK}^{\top 172}$, total AMPK, p-ACC ${ }^{579}$, p-p38 MAPK ${ }^{\top 180}$, and total p38 MAPK (all from Cell Signalling Technologies except p-ACC ${ }^{579}$ which was from Millipore). After incubation, membranes were washed thoroughly in TBS-T and incubated with a 1:4000 dilution of anti-species IgG horseradish peroxidaseconjugated secondary antibodies made up in blocking solution. After further washes, 
membranes were exposed to an enhanced chemiluminescence reagent and visualised using a chemiluminescent imager (EpiChemi II Darkroom, UVP, Upland, Canada). Band densities were quantified using Labworks Image Acquisition and Analysis Software Version 4.0.0.8 for Windows (UVP, Upland, Canada). All samples taken from each subject were run on the same gel. Blots for $p$-AMPK and p-p38 were normalised to the total amount of each respective protein, and $\mathrm{p}-\mathrm{ACC}$ was normalised to total AMPK content. Post-exercise time-points were expressed as a fold-change relative to pre-exercise values. Due to poor sample quality we were unable to analyse two samples at $\mathrm{t}=0$ and one at $\mathrm{t}=180$. These missing data points have been replaced with the mean response for the group at that time point for the purpose of statistical analysis.

\section{Real-time PCR}

Gene expression analysis was performed on muscle samples collected at baseline and 180 min post-exercise for samples with sufficient tissue left after analysis of glycogen and protein levels $(n=5)$. Total RNA was extracted from $\sim 10 \mathrm{mg}$ of frozen muscle using Trizol reagent according to the manufacturer's instructions (Life Technologies Ltd, Paisley, UK). Briefly, samples were suspended in $1 \mathrm{ml}$ of Trizol, homogenized using a mechanical glassTeflon (or Potter-Elvenheim) homogeniser, and then mixed with chloroform to produce an aqueous RNA phase which was subsequently mixed with isopropanol to precipitate RNA. The resulting RNA pellet was then washed with $75 \%$ ethanol, dried and resuspended in nucleasefree water. RNA quantity and quality was subsequently assessed using a NanoVue spectrophotometer (Thermo Fisher Scientific, Leicester, UK). RNA samples with a ratio of absorbance at 260 and $280 \mathrm{~nm}$ of $<1.6$ were considered of poor quality and were not processed further. RNA was stored at $-80^{\circ} \mathrm{C}$ before being reverse-transcribed to CDNA using the High-Capacity cDNA Reverse Transcription Kit with RNase Inhibitor (Life Technologies, Paisley, UK). Quantitative real-time PCR for GLUT4 (Hs00168966_m1) and PGC1 $\alpha$ (HS01016719_m1) relative to GAPDH (Hs.pt.39a.22214836; Integrated DNA technologies) was carried out using TaqMan Fast Universal, No AmpErase UNG chemistry in combination with a StepOne Fast 7500 real-time PCR system (all Applied Biosystems, Warrington, UK). cDNA (45 ng) was amplified under the following conditions: $95^{\circ} \mathrm{C}$ for $20 \mathrm{~s}$, followed by 40 cycles of $95^{\circ} \mathrm{C}$ for $3 \mathrm{~s}$ and $60^{\circ} \mathrm{C}$ for $30 \mathrm{~s}$. All PCR reactions were carried out in duplicate and a non-template control (i.e. nuclease-free water) was included for each housekeeping gene/gene of interest on all plates. The resulting amplification plots were used to generate $C_{T}$ values for genes of interest/housekeeping gene and the $\Delta C_{T}$ was calculated. The comparative $C_{T}$ method was used to calculate gene expression at $180 \mathrm{~min}$ post-exercise relative to baseline.

\section{Study 2}

\section{Subjects}

Eight healthy young men (mean \pm SD age: $21 \pm 2 \mathrm{y} ; \mathrm{BMl}: 25 \pm 4 \mathrm{~kg} \cdot \mathrm{m}^{-2}$; $\mathrm{VO}_{2}$ max: $39 \pm 10 \mathrm{ml} \cdot \mathrm{kg}^{-}$ $\left.{ }^{1} \cdot \mathrm{min}^{-1}\right)$ volunteered to take part in Study 2 . Subjects were requested to maintain their normal diet and patterns of physical activity throughout the study period. The study protocol was given ethics approval by the Research Ethics Approval Committee for Health (REACH 
Reference: EP 14/15 214) at the University of Bath and all subjects provided written informed consent after being advised of the full experimental procedures and potential risks.

\section{Pre-experimental procedures}

Prior to the main experimental trials subjects visited the laboratory on four separate occasions. During the initial visit subjects underwent a continuous incremental cycling test to determine $\dot{\mathrm{V}}_{2} \max$ as described above for Study 1 . Subjects next performed three familiarisation sessions (two for REHIT and one for aerobic exercise (AER)), each lasting approximately $15 \mathrm{~min}$. The AER familiarisation session was mainly used to check the intensity predicted to elicit $50 \%$ of $\dot{\mathrm{VO}}_{2}$ max. Subjects cycled for $10 \mathrm{~min}$ at the prescribed intensity and an expired air sample was collected during the final min. If necessary, adjustments were made to the intensity used during the main trials. The two REHIT familiarisation sessions were performed as described above for Study 1.

\section{Experimental procedures}

Subjects completed three main experimental trials (REHIT, AER and REST) in a randomised cross-over design. Subjects were asked to refrain from strenuous physical activity (2 days) and alcohol or caffeine ( 1 day) prior to each experimental trial. In addition, prior to the first trial a 24-hr food record was completed and subjects were asked to replicate this diet before each subsequent trial. To ensure adequate hydration subjects were asked to drink half a litre of water on the morning of each experimental trial.

Subjects reported to the laboratory between 8:30 and 9:30 am having fasted overnight from 10:00 pm the previous evening. After resting quietly for $15 \mathrm{~min}$, a 5-min baseline expired air sample, a venous blood sample, and subjective ratings of appetite and physical tiredness were collected as described below. These measurements were repeated at $0,15,30$ and 90 min post-exercise. During the post-exercise period subjects rested quietly and remained fasted with water allowed ad libitum throughout each trial.

Both exercise trials were performed on a mechanically-braked cycle ergometer (Monark 894E, Varberg, Sweden). In the AER condition subjects cycled continuously for 30 min at an intensity predicted to elicit $50 \%$ of $\mathrm{V}_{2}$ max. Heart rate, RPE and an expired air sample were collected during the final min of exercise. The REHIT trial involved 20 min of rest followed by the 10-min sprint interval bout described above for Study 1. Power output during the sprints was recorded continuously using Monark Anaerobic Test Software (Monark, Vansbro, Sweden), and used to calculate peak, average and end power output for each sprint. During the REST trial subjects rested quietly for $30 \mathrm{~min}$.

\section{Collection and analysis of expired air}

Subjects respired through a rubber mouthpiece connected to a two-way Hans Rudolph valve and expired air was collected into pre-evacuated Douglas bags. During each gas collection, samples of ambient (i.e. inspired) $\mathrm{CO}_{2}$ and $\mathrm{O}_{2}$ concentrations were measured within close proximity to the participant in order to account for small changes that could occur throughout the day in an enclosed laboratory environment (Betts and Thompson 2012). Expired concentrations of $\mathrm{O}_{2}$ and $\mathrm{CO}_{2}$ were measured using paramagnetic and infrared 
analysers respectively (Servomex miniMP 5200). Douglas bags were then completely evacuated using a dry gas meter (Harvard Apparatus, Kent, UK) and the total volume and temperature (Model $\mathrm{C}$, Edale Intruments, Cambridge, UK) were recorded for calculation of $\dot{\mathrm{VO}}_{2}, \mathrm{~V}_{\mathrm{CO}}$, and RER. All values were corrected to reflect standard temperature and pressures. In order to estimate EPOC, $\mathrm{VO}_{2}$ from the REST trial was subtracted from both of the exercise trials, excess $\mathrm{VO}_{2}$ from each 5 -min measurement period was totalled, and then total area under the oxygen curve was calculated.

\section{Blood collection and analysis}

Venous blood samples were collected through a cannula in an antecubital vein (BD Venflon Pro, BD, Helsingborg, Sweden). Haematocrit and haemoglobin concentrations were determined from 1-ml aliquots of EDTA-treated whole blood at each time point. Haematocrit was determined manually using a micro-centrifuge and Hawksley reader (Hawksley \& Sons Ltd, Sussex, UK). Haemoglobin concentration was analysed in duplicate on an automatic analyser (Sysmex R-3000, Sysmex Ltd, UK). Changes in plasma volume from baseline during each trial were calculated using published equations (Dill and Costill 1974). Hormone responses were corrected for changes in plasma volume. For plasma glucose both the uncorrected and corrected responses are presented.

For glucose, non-esterified fatty acids (NEFA), lactate and total PYY analysis, whole blood was dispensed into a 4-ml EDTA tube which was immediately spun at $3466 \mathrm{~g}$ and $4^{\circ} \mathrm{C}$ for 10 min to separate the plasma for storage at $-80^{\circ} \mathrm{C}$ until subsequent analysis. Automated analysers were used to analyse plasma lactate (YSI Stat 3000, Yellow Springs Instruments, Yellow Spring, $\mathrm{OH}$ ) and plasma glucose and NEFA (Randox Daytona, Country Antrim, UK). Plasma total PYY concentrations were analysed using commercially available ELISA (Millipore, Hertfordshire, UK). For analysis of acylated ghrelin $2 \mathrm{ml}$ of whole blood was first dispensed into a 4-ml EDTA tube containing $20 \mu \mathrm{l}$ of p-hydroxymercuribenzoic acid (PHMB). Samples were then spun at $3466 \mathrm{~g}$ for $10 \mathrm{~min}$ at $4^{\circ} \mathrm{C}$, and $500 \mu \mathrm{l}$ of the supernatant was transferred into a separate plain tube containing $50 \mu \mathrm{l}$ of $1 \mathrm{M} \mathrm{HCl}$ in order to preserve acylated ghrelin (Hosoda et al. 2004). Samples were then centrifuged again at $3466 \mathrm{~g}$ for 10 $\min$ at $4^{\circ} \mathrm{C}$ and the supernatant was transferred into a separate tube and frozen at $-80^{\circ} \mathrm{C}$ until subsequent analysis using a commercially available ELISA (Bertin Pharma, Montigny le Bretonneux, France). All plasma analyses were performed in duplicate.

Subjective ratings of tiredness and appetite

Perceptions of hunger and prospective food consumption were assessed using validated $100-\mathrm{mm}$ visual analogue scales with standard descriptors anchored at each end (Flint et al. 2000). Perceptions of physical tiredness were assessed using 100-mm visual analogue scales ranging from "not at all physically tired" to "as physically tired as I have ever felt".

\section{Statistical analysis}

All data are presented as mean \pm SEM. All data were analysed using the commercially available Statistics Package for Social Sciences (SPSS) software. Area-under-the-curve (AUC) calculations were performed using the trapezoid rule. For Study 1 , changes in skeletal 
muscle glycogen and signalling proteins were analysed using a one-way repeated-measures ANOVA. Post hoc comparisons were made using paired sample t-tests corrected using the Ryan-Holm Bonferroni stepwise adjustment. Changes in gene expression data from baseline to 180 min post-exercise were compared using a Wilcoxon Rank Sum Test as non-parametric tests are more appropriate when using small sample sizes (Siegel and Castellan 1988). For Study 2, two-way repeated measures ANOVAs (condition [REHIT, AER, REST] $\times$ time [Pre, 0 , $15,30,90]$ ) were used to analyse the response of all measured variables over time. Post hoc comparisons were made using paired sample t-tests corrected using the Ryan-Holm Bonferonni stepwise adjustment. Hormone AUCs were compared using one-way repeated measures ANOVA with post hoc paired sample t-tests. Significance was accepted at $\mathrm{P}<0.05$. 


\section{RESULTS}

\section{Study 1}

Peak, average and end power were $9.4 \pm 1.5,8.1 \pm 1.1$ and $6.2 \pm 1.1 \mathrm{~W} \cdot \mathrm{kg}^{-1}$ for the first sprint, and $8.4 \pm 1.6,7.2 \pm 1.2$ and $5.5 \pm 0.8 \mathrm{~W} \cdot \mathrm{kg}^{-1}$ for the second sprint. On average vastus lateralis glycogen concentration was reduced by $\sim 20 \%$ immediately post-exercise and remained reduced to a similar extent throughout the recovery period $(P<0.05$; Figure 1$)$. Phosphorylation of AMPK (Figure 2A) and p38 MAPK (Figure 2C) did not significantly change at any of the post-exercise time points, but ACC phosphorylation was strongly increased both immediately and 30 min post-exercise (both $P<0.05$ ), returning to baseline levels at 180 min (Figure 2B). At 180 min following exercise, gene expression was increased for PGC1 $\alpha$ $(16.5 \pm 6.2$ fold; $P<0.05)$ and tended to increase for GLUT4 $(2.2 \pm 0.6$ fold; $P=0.08$; Figure 3$)$.

\section{Study 2}

AER was performed at an average intensity of $86 \pm 5 \mathrm{~W}$, which elicited $53 \pm 5 \%$ of $\dot{\mathrm{VO}}_{2}$ max and $70 \pm 4 \%$ of maximum heart rate during the final min of exercise. Peak, average and end power for the REHIT session were $9.2 \pm 1.2,7.3 \pm 1.1$ and $5.5 \pm 1.1 \mathrm{~W} \cdot \mathrm{kg}^{-1}$ for the first sprint, and $8.2 \pm 1.4,6.5 \pm 1.1$ and $4.5 \pm 1.4 \mathrm{~W} \cdot \mathrm{kg}^{-1}$ for the second sprint.

Oxygen uptake and respiratory exchange ratio

Both exercise bouts increased $\dot{\mathrm{VO}}_{2}$ and RER relative to REST $(\mathrm{P}<0.01)$, but the magnitude of the increase was greater following REHIT for both variables $(\mathrm{P}<0.01 ;$ Table 1$)$. $\dot{\mathrm{VO}}_{2}$ returned to baseline levels $15 \mathrm{~min}$ after AER but remained elevated for at least $30 \mathrm{~min}$ following REHIT (all $P<0.05)$, resulting in a higher EPOC following REHIT compared with AER $(5.1 \pm 0.9 \mathrm{~L}$ vs. $1.0 \pm 0.8 \mathrm{~L} ; \mathrm{P}<0.01)$. Whilst RER returned to resting values at $15 \mathrm{~min}$ following $A E R$, following REHIT there was a decline in RER to below 0.70 at $30 \mathrm{~min}(P<0.01)$ and the decrease was still significant at 90 min post-exercise ( $P<0.05$ vs. AER and baseline, $P=0.18$ vs. REST).

\section{Blood parameters}

Both exercise bouts reduced plasma volume relative to REST $(P<0.001)$ but the decrease was more pronounced with REHIT ( $P<0.01$; Figure $4 \mathrm{~A})$. Whilst plasma volume had normalised at 15 min post-exercise in $A E R$, it remained reduced in REHIT at this time-point $(P<0.001$ vs. REST and AER). When uncorrected for plasma volume change, plasma glucose was increased directly after and 15 min after REHIT ( $P<0.05$; Figure 4B) whilst concentrations remained constant throughout the REST and AER trials. However, when plasma glucose concentrations were corrected for changes in plasma volume there were no changes in glucose levels following REHIT and a small reduction immediately post-exercise in AER compared with REST $(\mathrm{P}<0.05$; Figure $4 \mathrm{C})$. Both exercise bouts resulted in an increase in plasma lactate concentration relative to REST which persisted for at least $30 \mathrm{~min}$ following AER and at least 90 min following REHIT (all $\mathrm{P}<0.01$; Table 1). The increase in plasma lactate concentration was greater following REHIT compared with AER and concentrations remained higher at all measured time-points (all $\mathrm{P}<0.05$; Table 1). Plasma NEFA concentrations increased over time (main effect of time $\mathrm{P}<0.01$ ), but this effect was not changed by either exercise bout (Table 1). 
Plasma acylated ghrelin concentration decreased immediately after AER and REHIT compared with REST (both $\mathrm{P}<0.05$ ). Whilst concentrations were similar in AER and REHIT immediately post-exercise, they continued to decline in the REHIT trial only and were lower at 15 and 30 min post-exercise compared with both REST and AER ( $P<0.01$; Figure $5 \mathrm{~A})$. Post-

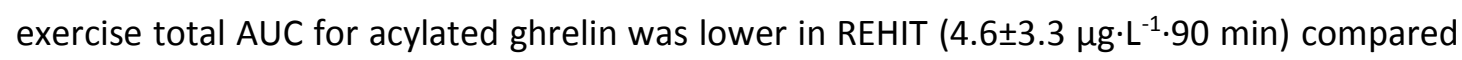
with REST $\left(8.8 \pm 4.7 \mu \mathrm{g} \cdot \mathrm{L}^{-1} .90 \mathrm{~min} ; \mathrm{P}<0.01\right)$ and AER $\left(8.9 \pm 5.5 \mu \mathrm{g} \cdot \mathrm{L}^{-1} .90 \mathrm{~min} ; \mathrm{P}<0.01\right)$. Plasma total PYY concentrations decreased over time (main effect of time $P<0.05$ ) but this effect was not altered by either exercise bout (Figure 5B).

\section{Subjective measures of appetite and tiredness}

Perception of physical tiredness was increased at 0 and $15 \mathrm{~min}$ following both exercise bouts $(\mathrm{P}<0.01$ and $\mathrm{P}<0.05$ vs. REST respectively), but tended to increase more following REHIT at $t=0(P=0.06$; Table 2). Perceptions of hunger and prospective food consumption increased over time (main effect of time $\mathrm{P}<0.05$ ), but these effects were not significantly altered by either exercise bout (Table 2). However, for prospective food consumption there was a tendency for lower ratings following REHIT ( $P=0.08$ for the time $\times$ condition interaction; Table 2). 


\section{DISCUSSION}

We have recently demonstrated that an exercise training intervention requiring a maximum of $40 \mathrm{~s}$ of high-intensity exercise within a 10-min cycling session (REHIT) can be effective in improving insulin sensitivity and maximal aerobic capacity over a 6-week period (Metcalfe et al. 2012). The aim of the two studies presented in this article was to characterise some of the acute molecular and physiological responses to a single REHIT session. In Study 1 we demonstrate that a 10-min REHIT session is sufficient to reduce skeletal muscle glycogen levels by a fifth and to increase the skeletal muscle mRNA expression of PGC1 $\alpha$, and GLUT4 (trend only). Although we were unable to detect a significant increase in AMPK or p38 MAPK phosphorylation, the robust activation and phosphorylation of the AMPK substrate ACC- $\beta$ at its AMPK phosphorylation site tentatively suggests that REHIT is associated with AMPK activation. In Study 2 we show that a 10-min REHIT session induces a markedly greater disturbance of homeostasis compared with $30 \mathrm{~min}$ of moderate-intensity aerobic exercise. Particularly noteworthy are the large changes in plasma volume, plasma lactate, and respiratory exchange ratio, all of which can directly or indirectly be explained by the rapid glycogen depletion observed in Study 1 . Although immediately after cessation of exercise ratings of physical tiredness were moderately higher for REHIT compared to AER, this difference had disappeared within $15 \mathrm{~min}$ after exercise, confirming our previous observations that REHIT is not considered overly strenuous by participants (Metcalfe et al. 2012). The substantial disturbance of physiological homeostasis, the activation of signalling pathways ultimately responsible for chronic training adaptations, the extreme timeefficiency, and the low associated perceived exertion and fatigue provide further support for the notion that low volumes of supramaximal exercise (e.g. REHIT) may provide a feasible alternative or adjunct to current physical activity recommendations for the general population.

\section{A crucial role for glycogen depletion?}

Whilst skeletal muscle glycogen has long been appreciated as an important acute regulator of skeletal muscle metabolism, accumulating evidence also supports its role as a signalling molecule potentiating exercise-induced adaptation (Philp et al. 2012; Jensen and Richter 2012). We originally designed our REHIT protocol based on the hypothesis that regular glycogen turnover may be sufficient to induce beneficial adaptations to insulin sensitivity, and we (Metcalfe et al. 2012) and others (Gillen et al. 2014) have indeed demonstrated that REHIT is associated with improved insulin sensitivity (at least in men). In the current study we demonstrate that REHIT is associated with an acute $20 \%$ reduction in vastus lateralis glycogen levels. These data confirm that glycogen degradation with REHIT is similar to that observed with HIT protocols incorporating a greater number of more prolonged (e.g. 3-4 $x$ 30 s) sprint efforts (Parolin et al. 1999; Gibala et al. 2009). This finding is supported by the data of Parolin et al (1999) who demonstrated that during three repeated 30-s all-out cycle sprints glycogen phosphorylase (and hence glycogenolysis) is predominantly activated during the first $15 \mathrm{~s}$ of the first sprint, and that further sprints break down little or no extra glycogen. 
Recent evidence has suggested an important role of glycogen availability in the activation of AMPK (McBride and Hardie 2009; McBride et al. 2009). Specifically, as AMPK has been shown to contain a glycogen-binding domain, a certain amount of AMPK will be bound within glycogen granules in a glycogen-replete state and this is associated with suppression of skeletal muscle AMPK activity (Philp et al. 2012). Likewise, exercise-induced glycogen depletion will result in a release of AMPK into the cytosol and a concomitant rise in AMPK activity (Philp et al. 2012), and this may be further enhanced in response to the expected rise in cytoplasmic AMP concentrations experienced particularly during high-intensity exercise (Karatzaferi et al. 2001b; Karatzaferi et al. 2001a). However, despite the fact that previous studies have observed significant increases in phosphorylation of AMPK with single and repeated Wingate sprint protocols (Gibala et al. 2009; Fuentes et al. 2012; Fuentes et al. 2013), we did not detect a significant increase in AMPK phosphorylation at any time-point following REHIT (although it should be noted that the numerical increase in AMPK phosphorylation $30 \mathrm{~min}$ post-exercise was similar to that observed in previous studies). Nonetheless, we did detect a robust activation and phosphorylation of ACC- $\beta$ at its AMPK phosphorylation site (Ha et al. 1994; Davies et al. 1990), and this suggests there may have been a level of AMPK activation which we were unable to detect. Indeed, some authors rely solely on ACC- $\beta$ phosphorylation as a marker of AMPK activity following exercise (Cochran et al. 2014; Little et al. 2011).

Another signalling molecule, p38 MAPK, has previously been shown to be activated following four repeated 30-second Wingate sprints (Gibala et al. 2009; Little et al. 2011). However, in accordance with a number of studies investigating single Wingate sprints (Gibala et al. 2009; Fuentes et al. 2012; Fuentes et al. 2013) we did not observe an increase in p38 MAPK phosphorylation. Whilst in the current study we have measured AMPK and p38 MAPK phosphorylation in a whole-muscle biopsy sample, the cellular localisation of these signalling proteins will likely also be of key importance for any adaptive response: regulation of gene transcription will either require direct translocation of the protein to the nucleus or a signalling cascade which transcends the nuclear membrane. Previous studies have observed translocation of AMPK and p38 MAPK to the cell nucleus during or in the recovery from an acute exercise bout (Little et al. 2011; Steinberg et al. 2006; Chan et al. 2004; McGee et al. 2003). Whether a similar response occurs with HIT/REHIT is a question for future research studies.

The significant increase in PGC1 $\alpha$ gene expression and the trend towards an increase in GLUT4 mRNA following REHIT also suggest the effective activation of adaptive signalling pathways such as that involving AMPK. This is supported by the recent findings that several markers of oxidative capacity in skeletal muscle, such as citrate synthase and COX IV, as well as protein levels of GLUT4 are increased following a 6-week REHIT intervention (Gillen et al. 2014). Although such responses have commonly been observed following a variety of submaximal and supramaximal HIT protocols (Gibala et al. 2009; Little et al. 2011; Little et al. 2010; Burgomaster et al. 2005; Hood et al. 2011; Gibala et al. 2006), the current study and that by Gillen et al (2014) together suggest that these responses may be achieved with a much smaller volume of exercise than previously thought. 
The absolute level of glycogen utilisation with HIT/REHIT is similar to that observed following a 30-min bout of moderate ( $50 \% \mathrm{VO}_{2} \mathrm{max}$ ) aerobic exercise (Van Loon et al. 2001). However, the speed at which the glycogenolysis occurs varies greatly between these two exercise modes. Indeed, the extremely rapid mobilisation of muscle glycogen is a unique characteristic of 'all-out' Wingate-type sprints, and likely explains much of the difference in the physiological disturbance observed with REHIT compared with aerobic exercise in the current study. Whilst with moderate aerobic exercise the rate of glycogenolysis will be matched closely with glucose oxidation, the considerable amount of glucose-6-phosphate released from glycogenolysis in the early stages of the initial REHIT sprint is likely to pose a substantial challenge to the intramyocellular milieu. Although the glycolytic catabolism of glucose-6-phosphate results in a rapid accumulation of pyruvate, only a small fraction of this is immediately oxidised; most is instead converted to lactate (Parolin et al. 1999), as evidenced by the large spike in plasma lactate concentration observed in our study. The strong reliance on glycolysis for ATP resynthesis will also result in a reduction in both intramyocellular and blood pH levels (Robergs et al. 2004). Consistent with previous observations following more strenuous and time-consuming HIT protocols (Chan and Burns 2013; Hazell et al. 2012) we observed a sharp increase in RER immediately after REHIT, demonstrating the immediate bicarbonate-mediated buffering of the metabolic acidosis associated with the all-out sprints. The subsequent drop in RER below 0.70 reflects the retention of $\mathrm{CO}_{2}$ to replenish the depleted blood bicarbonate stores during recovery (Laforgia et al. 1997). Given that the majority of glycogenolysis, and hence metabolic acidosis, occurs during the first sprint of a repeated sprint protocol (Parolin et al. 1999) it is not surprising that a protocol involving a smaller number of shorter sprints poses a similar challenge to buffering mechanisms compared with more strenuous HIT protocols, and hence still has this effect on RER (Hazell et al. 2012; Chan and Burns 2013). It can be speculated that this regular overloading (and recovery) of muscle and blood buffering mechanisms provides an explanation for the adaptations in buffering capacity observed following six weeks of HIT (Gibala et al. 2006).

A final consequence of the rapid glycogenolysis with REHIT is that the accumulation of metabolic derivatives will result in a hypertonic intramyocellular environment leading to an influx of water (Raja et al. 2006), which is consistent with the considerable drop in plasma volume we observed following REHIT. Potentially this subsequently places the myocyte in a transient state of osmotic stress (Haussinger 1996). Intriguingly, in various cell types osmotic swelling has previously been shown to independently activate various signalling cascades known to be involved in cellular remodelling (Haussinger 1996; Liu and Cao 2009). It is interesting to speculate whether this type of osmotic stress could be a mechanism of adaptation with HIT. From a practical research perspective however, a consequence of the substantial decrease in plasma volume following REHIT (which is presumably similar following other supramaximal HIT protocols), is that exercise-induced changes in plasma protein concentration should be corrected for plasma volume changes. Similarly, it seems reasonable to suggest that hemoconcentration due to the rapid drop in plasma volume may be responsible for previously observed increases in plasma glucose concentrations with 
sprint exercise (Vincent et al. 2004; Stokes et al. 2013; Esbjornsson et al. 2009), rather than an increase in glucose rate of appearance.

\section{REHIT may affect energy balance}

The current study demonstrates that circulating levels of the appetite-stimulating hormone acylated ghrelin are significantly reduced following REHIT, which with a total duration of 10 min makes it the lowest volume of exercise shown to be associated with such an effect to date. Furthermore, we demonstrated that EPOC is significantly greater following 10 min of REHIT compared to $30 \mathrm{~min}$ of moderate intensity aerobic exercise. These findings are of importance as several previous studies have observed reductions in fat mass following HIT with some evidence for superior reductions compared with traditional aerobic training (Whyte et al. 2010; Gillen et al. 2013; Heydari et al. 2012; Trapp et al. 2008). Since direct exercise energy expenditure is much lower with HIT compared with aerobic exercise, the (potentially superior) reductions in fat mass following HIT have been hypothesised to be a result of either an increase in energy expenditure through a more prolonged EPOC and/or a reduction in energy intake through suppression of appetite (Boutcher 2011). There are now several studies reporting that HIT results in an increase in total daily energy expenditure (Hazell et al. 2012; Skelly et al. 2014; Beaulieu et al. 2015; Sevits et al. 2013), and this increase is similar to that elicited by 30-50 minutes of moderate-vigorous aerobic exercise (Hazell et al. 2012; Skelly et al. 2014). However, the magnitude of the increase is typically modest and is only evident for 1-2 hours into the recovery period (Hazell et al. 2012; Skelly et al. 2014; Beaulieu et al. 2015; Sevits et al. 2013; Kelly et al. 2013; Williams et al. 2013; Chan and Burns 2013). In the present study we show that REHIT is associated with a 5 -fold greater EPOC compared with 30 min of moderate aerobic exercise, and the duration and magnitude of EPOC was similarly modest to protocols utilising a greater number and/or duration of sprints (Hazell et al. 2012; Skelly et al. 2014; Beaulieu et al. 2015; Sevits et al. 2013; Kelly et al. 2013; Williams et al. 2013; Chan and Burns 2013). On balance, the current state of evidence suggests that EPOC would only make a small contribution to any reduction in fat mass with HIT and certainly wouldn't explain any superior effects compared with continuous aerobic exercise (Hazell et al. 2012; Skelly et al. 2014).

It has also been suggested that HIT may result in suppression of appetite after exercise and hence lead to a reduction in energy intake across a training intervention (Boutcher 2011). The gut hormones acylated ghrelin (orexigenic effects) and PYY (anorexigenic effects) have emerged as important episodic regulators of hunger, feeding latency and caloric intake and may therefore play a role in mediating any changes in appetite with exercise (Stensel 2010; Wynne et al. 2005). Following REHIT systemic concentrations of acylated ghrelin were reduced by $>50 \%$ in the immediate post-exercise period, with little or no change observed following a bout of continuous cycling at a moderate intensity. This is consistent with other HIT studies (Sim et al. 2013; Deighton et al. 2013) and fits with previous research which highlights the key effect of relative exercise intensity on modulating the response of acylated ghrelin to aerobic exercise, with suppression occurring at higher ( $\geq 70 \% \dot{\mathrm{V}}_{2}$ max) but not lower ( $\leq 50 \% \dot{\mathrm{V}}_{2} \max$ ) exercise intensities (King et al. 2010; Ueda et al. 2009; Broom et al. 2007; Broom et al. 2009; Wasse et al. 2013). Conversely, circulating levels of total PYY 
appear to be unaffected by REHIT. The effect of other HIT protocols on total PYY is currently inconsistent with two studies demonstrating an increase in the immediate post-exercise period (Deighton et al. 2013; Beaulieu et al. 2015) and another showing no detectable changes (Sim et al. 2013). It is worth pointing out however that PYY values were not corrected for plasma volume changes in these studies (Deighton et al. 2013; Beaulieu et al. 2015); considering the large drop in plasma volume following REHIT in the current study any increase in PYY levels may partly have been caused by hemoconcentration.

Despite the strong attenuation of acylated ghrelin levels following REHIT there was no significant suppression of subjective ratings of appetite (although it is noteworthy that ratings of prospective food consumption tended to be lower in the REHIT trial). To date, there is limited data on the effects of HIT on indices of appetite and findings are equivocal (Deighton et al. 2013; Williams et al. 2013; Sim et al. 2013; Beaulieu et al. 2015). In young healthy males subjects two studies have observed a clear 'anorexic' effect of HIT on appetite-regulating hormones as well as subjective appetite ratings immediately post exercise, but this did not translate into a reduction in caloric intake during laboratory controlled ad libitum buffet meals (Deighton et al. 2013; Beaulieu et al. 2015). On the other hand, in a group of overweight men, there was a less robust effect of HIT on gut hormone responses and no effect on subjective appetite ratings, yet ad libitum energy intake during a laboratory-controlled breakfast meal and over the following day were both substantially reduced (Sim et al. 2013). Although the physiological relevance of short-term suppression of circulating levels of acylated ghrelin with HIT remains unclear, we can confirm this effect and demonstrate that it can be achieved with a substantially smaller amount of exercise than previously reported. Future research should look to further characterise the effect of REHIT on appetite and examine changes in body composition following a training intervention.

\section{Conclusions}

In conclusion, we demonstrate that REHIT is associated with a pronounced disturbance of homeostasis as evidenced by the rapid $\sim 20 \%$ reduction in skeletal muscle glycogen levels and the resulting large excursions in plasma volume, lactate levels and acid-base balance. This is accompanied by activation of adaptive signalling pathways as well as hormonal responses which together may explain previously observed training adaptations once thought to be exclusive to classic aerobic exercise. Together these data add further support to the growing awareness that the protocols used in previous HIT studies might be longer and more strenuous than necessary. A shift of focus towards studying lower volumes of high-intensity exercise may advance our quest to enable a larger proportion of the general population to reap the health benefits of regular physical activity.

\section{Acknowledgements}

We would like to thank Dr James Betts, Jacqueline Hutchinson, James Lloyd, Emily Mumford, Patrick Radley and Catherine Thomas for assistance with data collection, and Samantha Sargant for providing technical assistance with the biochemical analysis of the muscle 
samples. RSM is supported by a PhD studentship provided by the Department for Health, University of Bath. FK and GDH thank MRC, Diabetes UK and the British Heart Foundation for grant support.

\section{Conflict of interest}

The authors declare that there are no conflicts of interest. 


\section{REFERENCES}

Allender S, Scarborough P, Peto V, Rayner M, Leal J, Luengo-Fernandez R, Gray A (2008) European Cardiovascular Disease Statistics. European Heart Network, Brussels, England

Beaulieu K, Olver TD, Abbott KC, Lemon PW (2015) Energy intake over 2 days is unaffected by acute sprint interval exercise despite increased appetite and energy expenditure. Appl Physiol Nutr Metab 40 (1):79-86. doi:10.1139/apnm-2014-0229

Betts JA, Thompson D (2012) Thinking outside the bag (not necessarily outside the lab). Med Sci Sports Exerc 44 (10):2040. doi:10.1249/MSS.0b013e318264526f

Boutcher SH (2011) High-intensity intermittent exercise and fat loss. J Obes 2011:868305. doi:10.1155/2011/868305

Broom DR, Batterham RL, King JA, Stensel DJ (2009) Influence of resistance and aerobic exercise on hunger, circulating levels of acylated ghrelin, and peptide $Y Y$ in healthy males. Am J Physiol Regul Integr Comp Physiol 296 (1):R29-35. doi:10.1152/ajpregu.90706.2008

Broom DR, Stensel DJ, Bishop NC, Burns SF, Miyashita M (2007) Exercise-induced suppression of acylated ghrelin in humans. J Appl Physiol 102 (6):2165-2171. doi:10.1152/japplphysiol.00759.2006

Burgomaster KA, Howarth KR, Phillips SM, Rakobowchuk M, Macdonald MJ, McGee SL, Gibala MJ (2008) Similar metabolic adaptations during exercise after low volume sprint interval and traditional endurance training in humans. J Physiol 586 (1):151-160. doi:10.1113/jphysiol.2007.142109

Burgomaster KA, Hughes SC, Heigenhauser GJ, Bradwell SN, Gibala MJ (2005) Six sessions of sprint interval training increases muscle oxidative potential and cycle endurance capacity in humans. J Appl Physiol 98 (6):1985-1990. doi: 10.1152/japplphysiol.01095.2004

Chan HH, Burns SF (2013) Oxygen consumption, substrate oxidation, and blood pressure following sprint interval exercise. Appl Physiol Nutr Metab 38 (2):182-187. doi:10.1139/apnm-2012-0136

Chan MH, McGee SL, Watt MJ, Hargreaves M, Febbraio MA (2004) Altering dietary nutrient intake that reduces glycogen content leads to phosphorylation of nuclear p38 MAP kinase in human skeletal muscle: association with IL-6 gene transcription during contraction. FASEB J 18 (14):1785-1787. doi:10.1096/fj.03-1039fje

Cochran AJ, Percival ME, Tricarico S, Little JP, Cermak N, Gillen JB, Tarnopolsky MA, Gibala MJ (2014) Intermittent and continuous high-intensity exercise training induce similar acute but different chronic muscle adaptations. Exp Physiol 99 (5):782-791. doi:10.1113/expphysiol.2013.077453

Cocks M, Shaw CS, Shepherd SO, Fisher JP, Ranasinghe AM, Barker TA, Tipton KD, Wagenmakers AJ (2013) Sprint interval and endurance training are equally effective in 
increasing muscle microvascular density and eNOS content in sedentary males. J Physiol 591:641-656. doi:10.1113/jphysiol.2012.239566

Colley RC, Garriguet D, Janssen I, Craig CL, Clarke J, Tremblay MS (2011) Physical activity of Canadian adults: accelerometer results from the 2007 to 2009 Canadian Health Measures Survey. Health Rep 22 (1):7-14

Davies SP, Sim AT, Hardie DG (1990) Location and function of three sites phosphorylated on rat acetyl-CoA carboxylase by the AMP-activated protein kinase. Eur J Biochem 187 (1):183190. doi: 10.1111/j.1432-1033.1990.tb15293.x

Deighton K, Barry R, Connon CE, Stensel DJ (2013) Appetite, gut hormone and energy intake responses to low volume sprint interval and traditional endurance exercise. Eur J Appl Physiol 113 (5):1147-1156. doi:10.1007/s00421-012-2535-1

Dill DB, Costill DL (1974) Calculation of percentage changes in volumes of blood, plasma, and red cells in dehydration. J Appl Physiol 37 (2):247-248

Esbjornsson-Liljedahl M, Sundberg CJ, Norman B \& Jansson E (1999) Metabolic response in type I and type II muscle fibers during a 30-s cycle sprint in men and women. J Appl Physiol 87: 1326-1332.

Esbjornsson M, Norman B, Suchdev S, Viru M, Lindhgren A, Jansson E (2009) Greater growth hormone and insulin response in women than in men during repeated bouts of sprint exercise. Acta Physiol 197 (2):107-115. doi:10.1111/j.1748-1716.2009.01994.x

Flint A, Raben A, Blundell JE, Astrup A (2000) Reproducibility, power and validity of visual analogue scales in assessment of appetite sensations in single test meal studies. Int J Obes Relat Metab Disord 24 (1):38-48. doi: 10.1038/sj.ijo.0801083

Fuentes T, Guerra B, Ponce-González JG, Morales-Alamo D, Guadalupe-Grau A, Olmedillas H, Rodríguez-García L, Feijoo D, De Pablos-Velasco P, Fernández-Pérez L, Santana A, Calbet JA (2012) Skeletal muscle signalling response to sprint exercise in men and women. Eur J Appl Physiol 112 (5):1917-1927. doi:10.1007/s00421-011-2164-0

Fuentes T, Ponce-González JG, Morales-Alamo D, de Torres-Peralta R, Santana A, De PablosVelasco P, Olmedillas H, Guadalupe-Grau A, Rodríguez-García L, Serrano-Sanchez JA, Guerra B, Calbet JA (2013) Isoinertial and isokinetic sprints: muscle signalling. Int J Sports Med 34 (4):285-292. doi:10.1055/s-0032-1312583

Garber CE, Blissmer B, Deschenes MR, Franklin BA, Lamonte MJ, Lee IM, Nieman DC, Swain DP (2011) American College of Sports Medicine position stand. Quantity and quality of exercise for developing and maintaining cardiorespiratory, musculoskeletal, and neuromotor fitness in apparently healthy adults: guidance for prescribing exercise. Med Sci Sports Exerc 43 (7):1334-1359. doi:10.1249/MSS.0b013e318213fefb

Gibala MJ, Little JP, van Essen M, Wilkin GP, Burgomaster KA, Safdar A, Raha S, Tarnopolsky MA (2006) Short-term sprint interval versus traditional endurance training: similar initial 
adaptations in human skeletal muscle and exercise performance. J Physiol 575:901-911. doi:10.1113/jphysiol.2006.112094

Gibala MJ, McGee SL, Garnham AP, Howlett KF, Snow RJ, Hargreaves M (2009) Brief intense interval exercise activates AMPK and p38 MAPK signaling and increases the expression of PGC-1alpha in human skeletal muscle. J Appl Physiol 106 (3):929-934. doi:10.1152/japplphysiol.90880.2008

Gillen JB, Gibala MJ (2014) Is high-intensity interval training a time-efficient exercise strategy to improve health and fitness? Appl Physiol Nutr Metab 39 (3):409-412. doi:10.1139/apnm2013-0187

Gillen JB, Percival ME, Ludzki A, Tarnopolsky MA, Gibala MJ (2013) Interval training in the fed or fasted state improves body composition and muscle oxidative capacity in overweight women. Obes. doi:10.1002/oby.20379

Gillen JB, Percival ME, Skelly LE, Martin BJ, Tan RB, Tarnopolsky MA, Gibala MJ (2014) Three minutes of all-out intermittent exercise per week increases skeletal muscle oxidative capacity and improves cardiometabolic health. PLoS One 9 (11):e111489. doi:10.1371/journal.pone.0111489

Ha J, Daniel S, Broyles SS, Kim KH (1994) Critical phosphorylation sites for acetyl-CoA carboxylase activity. J Biol Chem 269 (35):22162-22168

Haussinger D (1996) The role of cellular hydration in the regulation of cell function. Biochem J 313:697-710

Hazell TJ, Macpherson RE, Gravelle BM, Lemon PW (2010) 10 or 30-s sprint interval training bouts enhance both aerobic and anaerobic performance. Eur J Appl Physiol 110 (1):153-160. doi:10.1007/s00421-010-1474-y

Hazell TJ, Olver TD, Hamilton CD, Lemon PW (2012) Two minutes of sprint-interval exercise elicits 24-hr oxygen consumption similar to that of $30 \mathrm{~min}$ of continuous endurance exercise. Int J Sport Nutr Exerc Metab 22 (4):276-283

Heydari M, Freund J, Boutcher SH (2012) The effect of high-intensity intermittent exercise on body composition of overweight young males. J Obes 2012:480467. doi:10.1155/2012/480467

Hood MS, Little JP, Tarnopolsky MA, Myslik F, Gibala MJ (2011) Low-volume interval training improves muscle oxidative capacity in sedentary adults. Med Sci Sports Exerc 43 (10):18491856. doi:10.1249/MSS.0b013e3182199834

Hosoda H, Doi K, Nagaya N, Okumura H, Nakagawa E, Enomoto M, Ono F, Kangawa K (2004) Optimum collection and storage conditions for ghrelin measurements: octanoyl modification of ghrelin is rapidly hydrolyzed to desacyl ghrelin in blood samples. Clin Chem 50 (6):10771080. doi:10.1373/clinchem.2003.025841 
Jensen TE, Richter EA (2012) Regulation of glucose and glycogen metabolism during and after exercise. J Physiol 590:1069-1076. doi:10.1113/jphysiol.2011.224972

Karatzaferi C, de Haan A, Ferguson RA, van Mechelen W, Sargeant AJ (2001a) Phosphocreatine and ATP content in human single muscle fibres before and after maximum dynamic exercise. Pflugers Arch 442 (3):467-474. doi: 10.1007/s004240100552

Karatzaferi C, de Haan A, van Mechelen W, Sargeant AJ (2001b) Metabolism changes in single human fibres during brief maximal exercise. Exp Physiol 86 (3):411-415. doi: $10.1113 /$ eph8602223

Kelly B, King JA, Goerlach J, Nimmo MA (2013) The impact of high-intensity intermittent exercise on resting metabolic rate in healthy males. Eur J Appl Physiol 113 (12):3039-3047. doi:10.1007/s00421-013-2741-5

King JA, Wasse LK, Broom DR, Stensel DJ (2010) Influence of brisk walking on appetite, energy intake, and plasma acylated ghrelin. Med Sci Sports Exerc 42 (3):485-492. doi:10.1249/MSS.0b013e3181ba10c4

Korkiakangas EE, Alahuhta MA, Laitinen JH (2009) Barriers to regular exercise among adults at high risk or diagnosed with type 2 diabetes: a systematic review. Health Promot Int 24 (4):416-427. doi:10.1093/heapro/dap031

Laforgia J, Withers RT, Shipp NJ, Gore CJ (1997) Comparison of energy expenditure elevations after submaximal and supramaximal running. J Appl Physiol 82 (2):661-666

Little JP, Safdar A, Bishop D, Tarnopolsky MA, Gibala MJ (2011) An acute bout of highintensity interval training increases the nuclear abundance of PGC-1 $\alpha$ and activates mitochondrial biogenesis in human skeletal muscle. Am J Physiol Regul Integr Comp Physiol 300 (6):R1303-1310. doi:10.1152/ajpregu.00538.2010

Little JP, Safdar A, Wilkin GP, Tarnopolsky MA, Gibala MJ (2010) A practical model of lowvolume high-intensity interval training induces mitochondrial biogenesis in human skeletal muscle: potential mechanisms. J Physiol 588:1011-1022. doi:10.1113/jphysiol.2009.181743

Liu Z, Cao W (2009) p38 mitogen-activated protein kinase: a critical node linking insulin resistance and cardiovascular diseases in type 2 diabetes mellitus. Endocr Metab Immune Disord Drug Targets. 9 (1):38-46. doi: 10.2174/187153009787582397

McBride A, Ghilagaber S, Nikolaev A, Hardie DG (2009) The glycogen-binding domain on the AMPK beta subunit allows the kinase to act as a glycogen sensor. Cell Metab 9 (1):23-34. doi:10.1016/j.cmet.2008.11.008

McBride A, Hardie DG (2009) AMP-activated protein kinase-a sensor of glycogen as well as AMP and ATP? Acta Physiol 196 (1):99-113. doi:10.1111/j.1748-1716.2009.01975.x 
McGee SL, Howlett KF, Starkie RL, Cameron-Smith D, Kemp BE, Hargreaves M (2003) Exercise increases nuclear AMPK alpha2 in human skeletal muscle. Diabetes 52 (4):926-928. doi: 10.2337/diabetes.52.4.926

Metcalfe RS, Babraj JA, Fawkner SG, Vollaard NB (2012) Towards the minimal amount of exercise for improving metabolic health: beneficial effects of reduced-exertion high-intensity interval training. Eur J Appl Physiol 112 (7):2767-2775. doi:10.1007/s00421-011-2254-z

Parolin ML, Chesley A, Matsos MP, Spriet LL, Jones NL, Heigenhauser GJ (1999) Regulation of skeletal muscle glycogen phosphorylase and PDH during maximal intermittent exercise. Am J Physiol 277 (5 Pt 1):E890-900

Perry CG, Lally J, Holloway GP, Heigenhauser GJ, Bonen A \& Spriet LL. (2010). Repeated transient mRNA bursts precede increases in transcriptional and mitochondrial proteins during training in human skeletal muscle. J Physiol 588: 4795-4810. doi: 10.1113/jphysiol.2010.199448.

Philp A, Hargreaves M, Baar K (2012) More than a store: regulatory roles for glycogen in skeletal muscle adaptation to exercise. Am J Physiol Endocrinol Metab 302 (11):E1343-1351. doi:10.1152/ajpendo.00004.2012

Raja MK, Raymer GH, Moran GR, Marsh G, Thompson RT (2006) Changes in tissue water content measured with multiple-frequency bioimpedance and metabolism measured with 31P-MRS during progressive forearm exercise. J Appl Physiol 101 (4):1070-1075. doi:10.1152/japplphysiol.01322.2005

Rakobowchuk M, Tanguay S, Burgomaster KA, Howarth KR, Gibala MJ, MacDonald MJ (2008) Sprint interval and traditional endurance training induce similar improvements in peripheral arterial stiffness and flow-mediated dilation in healthy humans. Am J Physiol Regul Integr Comp Physiol 295 (1):R236-242. doi:10.1152/ajpregu.00069.2008

Reichert FF, Barros AJ, Domingues MR, Hallal PC (2007) The role of perceived personal barriers to engagement in leisure-time physical activity. Am J Public Health 97 (3):515-519. doi:10.2105/AJPH.2005.070144

Robergs RA, Ghiasvand F, Parker D (2004) Biochemistry of exercise-induced metabolic acidosis. Am J Physiol Regul Integr Comp Physiol 287 (3):R502-516. doi:10.1152/ajpregu.00114.2004

Sevits KJ, Melanson EL, Swibas T, Binns SE, Klochak AL, Lonac MC, Peltonen GL, Scalzo RL, Schweder MM, Smith AM, Wood LM, Melby CL, Bell C (2013) Total daily energy expenditure is increased following a single bout of sprint interval training. Physiol Rep 1 (5):e00131. doi:10.1002/phy2.131

Shepherd SO, Cocks M, Tipton KD, Ranasinghe AM, Barker TA, Burniston JG, Wagenmakers AJ, Shaw CS (2013) Sprint interval and traditional endurance training increase net intramuscular triglyceride breakdown and expression of perilipin 2 and 5. J Physiol 591:657675. doi:10.1113/jphysiol.2012.240952 
Siegel S \& Castellan NJ. (1988). Nonparametric statistics for the behavioral sciences. McGraw-Hill, New York ; London.

Sim AY, Wallman KE, Fairchild TJ, Guelfi KJ (2013) High-intensity intermittent exercise attenuates ad-libitum energy intake. Int J Obes 38(3):417-22. doi:10.1038/ijo.2013.102

Skelly LE, Andrews PC, Gillen JB, Martin BJ, Percival ME, Gibala MJ (2014) High-intensity interval exercise induces 24-h energy expenditure similar to traditional endurance exercise despite reduced time commitment. Appl Physiol Nutr Metab 39 (7):845-848. doi:10.1139/apnm-2013-0562

Steinberg GR, Watt MJ, McGee SL, Chan S, Hargreaves M, Febbraio MA, Stapleton D, Kemp BE (2006) Reduced glycogen availability is associated with increased AMPKalpha2 activity, nuclear AMPKalpha2 protein abundance, and GLUT4 mRNA expression in contracting human skeletal muscle. Appl Physiol Nutr Metab 31 (3):302-312. doi:10.1139/h06-003

Stensel D (2010) Exercise, appetite and appetite-regulating hormones: implications for food intake and weight control. Ann Nutr Metab 57 (2):36-42. doi:10.1159/000322702

Stokes KA, Gilbert KL, Hall GM, Andrews RC, Thompson D (2013) Different responses of selected hormones to three types of exercise in young men. Eur J Appl Physiol 113 (3):775783. doi:10.1007/s00421-012-2487-5

Tarnopolsky MA, Pearce E, Smith K, Lach B (2011) Suction-modified Bergström muscle biopsy technique: experience with 13,500 procedures. Muscle Nerve 43 (5):717-725. doi:10.1002/mus.21945

Tjønna AE, Leinan IM, Bartnes AT, Jenssen BM, Gibala MJ, Winett RA, Wisløff U (2013) Lowand high-volume of intensive endurance training significantly improves maximal oxygen uptake after 10-weeks of training in healthy men. PLoS One 8 (5):e65382. doi:10.1371/journal.pone.0065382

Trapp EG, Chisholm DJ, Freund J, Boutcher SH (2008) The effects of high-intensity intermittent exercise training on fat loss and fasting insulin levels of young women. Int $J$ Obes 32 (4):684-691. doi:10.1038/sj.ijo.0803781

Tucker JM, Welk GJ, Beyler NK (2011) Physical activity in U.S.: adults compliance with the Physical Activity Guidelines for Americans. Am J Prev Med 40 (4):454-461. doi:10.1016/j.amepre.2010.12.016

Ueda SY, Yoshikawa T, Katsura Y, Usui T, Nakao H, Fujimoto S (2009) Changes in gut hormone levels and negative energy balance during aerobic exercise in obese young males. J Endocrinol 201 (1):151-159. doi:10.1677/JOE-08-0500

van Loon LJC, Greenhaff PL, Teodosiu DC, Saris WHM \& Wagenmakers AJM (2001) The effects of increasing exercise intensity on muscle fuel utilisation in humans. J Physiol 536: 295-304. doi: 10.1111/j.1469-7793.2001.00295.x 
Vincent S, Berthon P, Zouhal H, Moussa E, Catheline M, Bentue-Ferrer D, Gratas-Delamarche A (2004) Plasma glucose, insulin and catecholamine responses to a Wingate test in physically active women and men. Eur J Appl Physiol 91 (1):15-21. doi:10.1007/s00421-003-0957-5

Wasse LK, Sunderland C, King JA, Miyashita M, Stensel DJ (2013) The influence of vigorous running and cycling exercise on hunger perceptions and plasma acylated ghrelin concentrations in lean young men. Appl Physiol Nutr Metab 38 (1):1-6. doi:10.1139/apnm2012-0154

Whyte LJ, Gill JM, Cathcart AJ (2010) Effect of 2 weeks of sprint interval training on healthrelated outcomes in sedentary overweight/obese men. Metabolism 59 (10):1421-1428. doi:10.1016/j.metabol.2010.01.002

Williams CB, Zelt JGE, Castellani LN, Little JP, Jung ME, Wright DC, Tschakovsky ME, Gurd BJ (2013) Changes in mechanisms proposed to mediate fat loss following an acute bout of highintensity interval and endurance exercise. Appl Physiol Nutr Metab 38. doi:10.1139/apnm2013-0101

Wynne K, Stanley S, McGowan B, Bloom S (2005) Appetite control. J Endocrinol 184 (2):291318. doi:10.1677/joe.1.05866 
Table 1 Changes in $\dot{\mathrm{VO}}_{2}$, RER, plasma lactate and plasma NEFA

\begin{tabular}{|c|c|c|c|c|c|c|}
\hline & & \multirow[b]{2}{*}{ Pre } & \multicolumn{4}{|c|}{ Post-exercise time (min) } \\
\hline & & & $0-5$ & $15-20$ & $30-35$ & $90-95$ \\
\hline \multirow{2}{*}{$\dot{\mathrm{VO}}_{2}$} & REST & $0.31 \pm 0.02$ & $0.29 \pm 0.02$ & $0.29 \pm 0.02$ & $0.28 \pm 0.02$ & $0.30 \pm 0.02$ \\
\hline & AFR & ב0 ח 031 & $0 \Delta 6+00 \Delta^{+}$ & ב0 ח 031 & ב0 ח+30 0 & בח ח+30 0 \\
\hline \multirow{2}{*}{$\left(L \cdot \mathrm{min}^{-1}\right)$} & REHIT & $0.30 \pm 0.02$ & $0.62 \pm 0.04 * \#$ & $0.38 \pm 0.02 * \#$ & $0.34 \pm 0.02 * \#$ & $0.31 \pm 0.02$ \\
\hline & REST & $0.84 \pm 0.01$ & $0.82 \pm 0.01$ & $0.81 \pm 0.02$ & $0.82 \pm 0.01$ & $0.81 \pm 0.01$ \\
\hline \multirow[t]{3}{*}{ RER } & AER & $0.86 \pm 0.02$ & $1.04 \pm 0.02^{+}$ & $0.82 \pm 0.03$ & $0.81 \pm 0.02$ & $0.83 \pm 0.02$ \\
\hline & REHIT & $0.82 \pm 0.02$ & $1.29 \pm 0.03 * \#$ & $0.76 \pm 0.02 * \#$ & $0.68 \pm 0.01^{* \#}$ & $0.75 \pm 0.02^{\#}$ \\
\hline & & Pre & 0 & 15 & 30 & 90 \\
\hline \multirow{2}{*}{$\begin{array}{l}\text { Plasma } \\
\text { lactate }\end{array}$} & REST & $1.45 \pm 0.20$ & $1.03 \pm 0.11$ & $1.01 \pm 0.12$ & $1.00 \pm 0.13$ & $1.00 \pm 0.12$ \\
\hline & AER & $1.88 \pm 0.39$ & $3.54 \pm 0.64^{+}$ & $1.88 \pm 0.27^{\dagger}$ & $1.41 \pm 0.16^{+}$ & $1.12 \pm 0.13$ \\
\hline$\left(\mathrm{mmol} \cdot \mathrm{L}^{-1}\right)$ & REHIT & $1.51 \pm 0.35$ & $15.37 \pm 1.25^{* \#}$ & $12.51 \pm 0.99^{* \#}$ & $7.73 \pm 0.73^{* \#}$ & $1.88 \pm 0.18^{* \#}$ \\
\hline \multirow{3}{*}{ Plasma NEFA } & REST & $0.46 \pm 0.09$ & $0.45 \pm 0.07$ & $0.47 \pm 0.07$ & $0.54 \pm 0.08$ & $0.66 \pm 0.08$ \\
\hline & AER & $0.43 \pm 0.09$ & $0.46 \pm 0.11$ & $0.60 \pm 0.14$ & $0.46 \pm 0.10$ & $0.57 \pm 0.12$ \\
\hline & REHIT & $0.46 \pm 0.05$ & $0.34 \pm 0.04$ & $0.39 \pm 0.06$ & $0.36 \pm 0.05$ & $0.58 \pm 0.06$ \\
\hline
\end{tabular}

Data are presented as mean $\pm \operatorname{SEM}(n=8) .{ }^{*} P<0.05$ for REHIT vs. $R E S T$; $+P<0.05$ for AER vs. REST; $\# P<0.05$ for REHIT vs. AER. 
Table 2 Changes in subjective perceptions of physical tiredness, hunger and prospective food consumption

\begin{tabular}{|c|c|c|c|c|c|c|}
\hline & & \multicolumn{5}{|c|}{ Post-exercise time (min) } \\
\hline & & Pre & $\mathbf{0}$ & 15 & 30 & 90 \\
\hline \multirow{2}{*}{ Physical tiredness } & REST & $15 \pm 3$ & $16 \pm 7$ & $14 \pm 6$ & $14 \pm 7$ & $16 \pm 8$ \\
\hline & AER & $16+6$ & $41+7^{+}$ & $28+7^{+}$ & $21+7^{+}$ & $16 \pm 7$ \\
\hline$(0-100 \mathrm{~mm})$ & RFHIT & $13+5$ & $58+6 * \#$ & $27+7 *$ & $22+7 *$ & $16+7$ \\
\hline \multirow{2}{*}{ Hunger } & REST & $36 \pm 11$ & $42 \pm 11$ & $45 \pm 12$ & $49 \pm 11$ & $55 \pm 10$ \\
\hline & AER & $33 \pm 10$ & $45 \pm 10$ & $46 \pm 10$ & $46 \pm 10$ & $53 \pm 8$ \\
\hline$(0-100 \mathrm{~mm})$ & REHIT & $30 \pm 8$ & $37 \pm 9$ & $38 \pm 9$ & $37 \pm 9$ & $42 \pm 8$ \\
\hline \multirow{2}{*}{$\begin{array}{l}\text { Prospective food } \\
\text { consumption } \$\end{array}$} & REST & $43 \pm 10$ & $46 \pm 11$ & $50 \pm 10$ & $55 \pm 10$ & $59 \pm 9$ \\
\hline & AER & $37 \pm 10$ & $54 \pm 9$ & $53 \pm 9$ & $54 \pm 8$ & $59 \pm 7$ \\
\hline$(0-100 \mathrm{~mm})$ & REHIT & $36 \pm 8$ & $42 \pm 8$ & $38 \pm 8$ & $39 \pm 9$ & $45 \pm 8$ \\
\hline
\end{tabular}

Data are presented as mean $\pm S E M(n=8) . \$ P<0.05$ for time main effect; ${ }^{*} P<0.05$ for REHIT vs. REST; $+P<0.05$ for AER vs. REST; \#P<0.05 for REHIT vs. AER. 
Figure 1 The effect of REHIT on vastus lateralis glycogen concentration

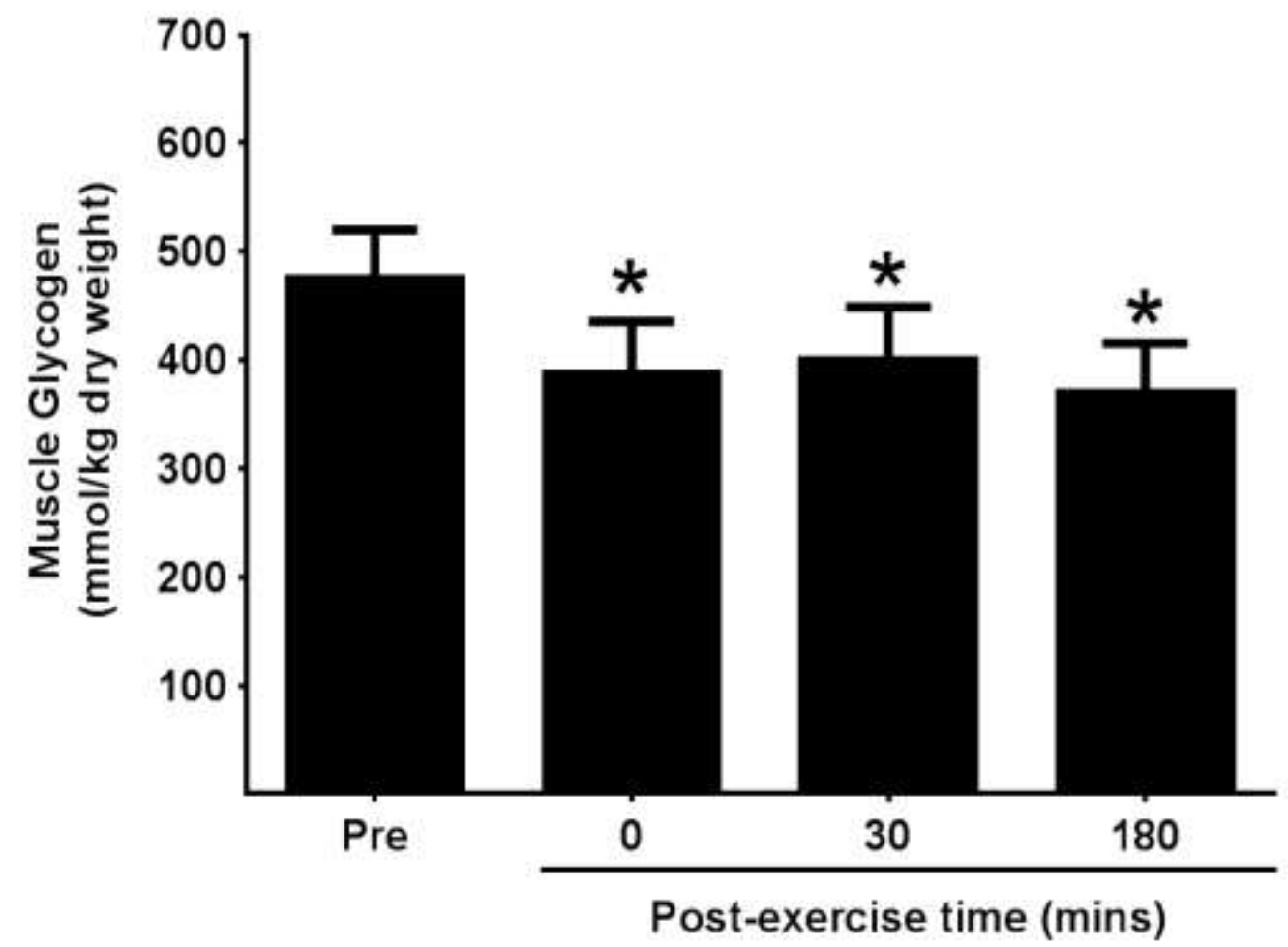

Data are presented as mean $\pm S E M(n=11) .{ }^{*} P<0.05$ vs. pre. 
Figure 2 The effect of REHIT on phosphorylation of AMPK (A), ACC (B), and p38 MAPK (C)
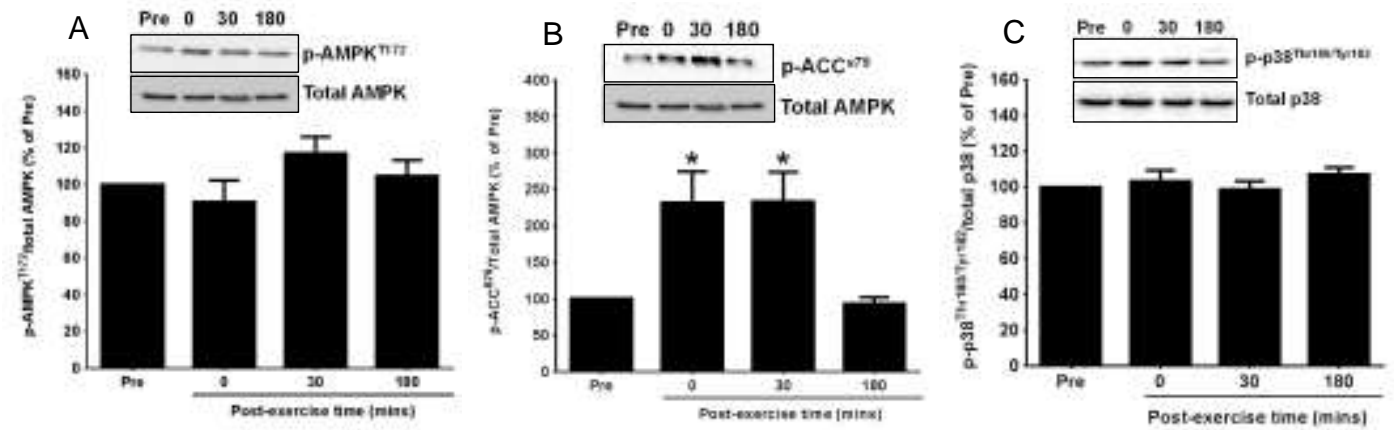

Data are presented as mean \pm SEM ( $n=11) .{ }^{*} P<0.05$ vs. pre. Representative blots are shown above each respective figure. 
Figure 3 Gene expression changes for PGC1 $\alpha$ (A) and GLUT4 (B) at $180 \mathrm{~min}$ postexercise
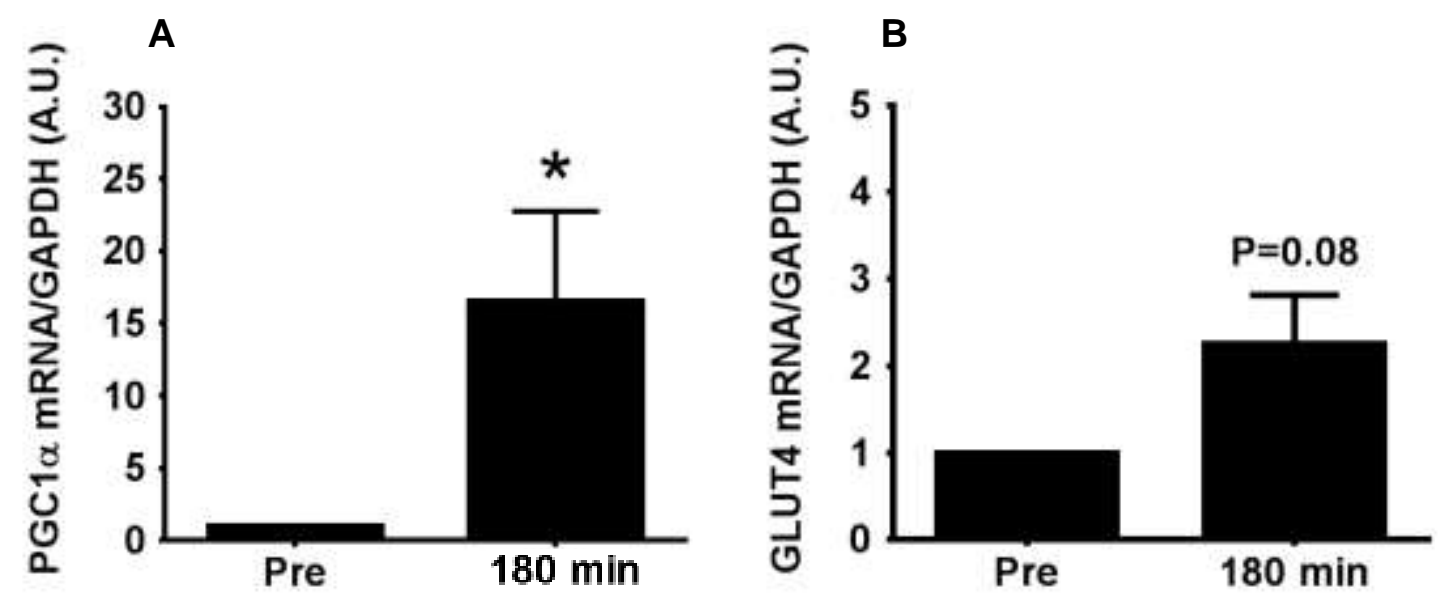

Data are presented as mean \pm SEM ( $n=5)$. ${ }^{*}$ denotes $P<0.05$ vs. pre 
Figure 4 Changes in plasma volume (A), and uncorrected (B) and corrected (C) plasma glucose responses
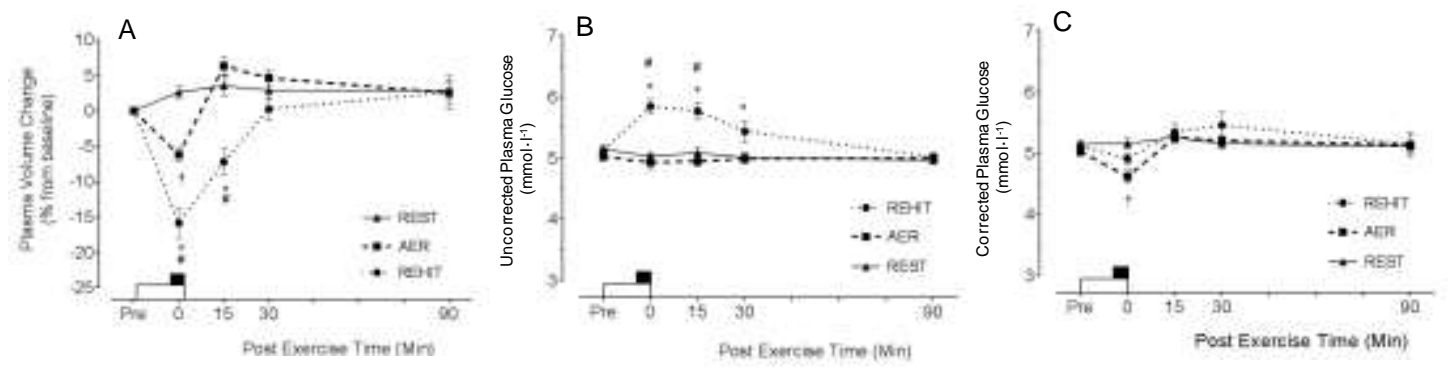

Data are presented as mean \pm SEM ( $n=8)$. White box: aerobic exercise; black box: REHIT. ${ }^{*} P<0.05$ for REHIT vs. REST; $\# P<0.05$ for REHIT vs. AER; $+P<0.05$ for $A E R$ vs. REST. 
Figure $5 \quad$ Changes in plasma acylated ghrelin (A) and PYY (B) concentrations
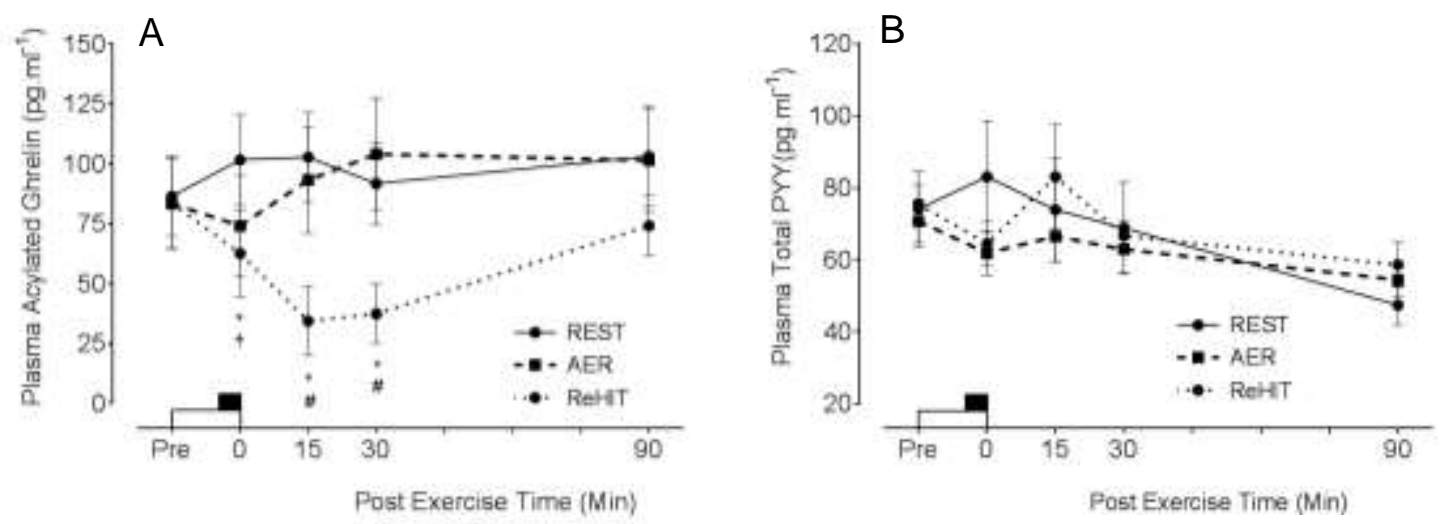

Data are presented as mean $\pm \operatorname{SEM}(n=8)$. White box: aerobic exercise; black box: REHIT. * denotes $P<0.05$ for REHIT vs. REST; \# denotes $P<0.05$ for REHIT vs. AER; + denotes $P<0.05$ for AER vs. REST. Values have been corrected for changes in plasma volume. 